departments of the army were confronted with a great labor, providing for a quarter of a million of men suddenly called into the field. Full outfits of medical and surgical chests for regiments and for division hospitals, with ambulances, tents, cots, etc., were shipped off rapidly from the purveying depots so rapidly that transportation companies had difficulty in delivering their freight; and these things had to be made, they were not to be purchased in any drug store or wheelwright's shop. I need say no more of these conditions. They are readily understood by men of intelligence, few of whom will agree with Dr. Cuthbertson, that "if numbers of medical men whom he could name had been placed at the head of affairs, our whole army would have been completely equipped with every medical and surgical necessity they could require in three days." Respectfully yours,

Charles Smart, Lieut.-Colonel, Deputy Surgeon-General, U. S. Army.

\section{The "Incompetent and Inefficient" Medical Department of the Army.}

NEw York, Aug. 27, 1898.

To the Editor:-I have all along sympathized with SurgeonGeneral Sternberg for the load he has had to bear; but I did not fully appreciate the bearing of his burthen until I read the letter in your issue of August 20, (pp. 421-3). The wail of the "Late Major and Surgeon" [hinc ille lachryma] recalls the complaint of the governor of a great State that the medical officers of the regiments from that State "could not get their prescriptions filled," who, when confronted with the Army Medical Supply Table, and told that it was the fault of those officers if they lacked anything, said: "Oh, yes, I have seen that, but I would like you to show me lactopeptin on it." "Lactopeptin! What would they want with lactopeptin?" "Why," said he, "most of these men have not been accus. tomed to the coarse army fare and they required lactopeptin to be able to digest it."

Who would not be Surgeon-General of the Army?

Fortunately there is balm in Gilead. Let the Red Cross see that every soldier's "panties" shall have two extra pockets, one for a bottle of lactopeptin and the other for that "splendid little machine," commended by Clara Barton (Feb. 21, 1896), the Electropoise ; or, perhaps, these pockets had better be put in their pajamas, the lactopeptin to insure the digestion of the "coarse army fare," and the Electropoise, "that incalculable blessing," which has "power to put a person to sleep and keep him asleep until satisfied Nature awakes refreshed," to protect him against night alarms.

About six weeks ago some charitably-disposed ladies offered a naval purveying officer an unlimited supply of catnip for the sailors in the navy. Why should not catnip be equally serviceable to soldiers? If every one in the United States will only suggest what he or she thinks ought to be added to the Army Medical Supply Table, the Medical Department of the Army may in time become not quite so "incompetent and inefficient." The Association of Military Surgeons of the United States might profitably consider this matter at its post-bellum meeting.

\section{The Association and the Colleges.}

Trenton, Tenn., Aug. 22, 1898.

To the Editor:-After carefully reading the notice sent out by Dr. W. B. A tkinson, Permanent Secretary, to the deans of the various Medical Colleges in the United States, setting forth the action of the American Medical Association, at Denver, in June last, in which it was voted " to allow no one to register as either delegate or permanent member of this Association," who, as "professor or other teacher in, or graduate of any Medical College in the United States, which shall, after Jan. 1, 1899, confer the degree of Doctor of Medicine, or receive such degree on any condition below the published standard of the Association of American Medical Colleges," I am satisfied that the Association has attempted to reach a point which it should attain, in an unconstitutional manner. This resolution attempts to define who shall be received hereafter as members of this Association, and in doing this certainly is amending section 2 of our Constitution, which clearly defines the membership of the American Medical AssociaTION, and as such should be laid over for one year. (See section 7, page 9 of Constitution.) Had this point of order been. made against the resolution at the time it was offered, as the presiding officer of the Association on that day, I would have decided the point well taken, and have ruled it out of order.

It is a point of law that any action improperly taken, unlawfully passed, is not binding. Hence, it seems to me, that. to make such action binding, the matter must be presented in the form of an amendment, lie over one year, and then be acted on. This matter is one of too much importance to the Association to be rushed through in the hurry of business with the assurance from the Secretary of Business Committee that one member of the Southern Medical College Association assured him that they were all ready to abide by the action of the Association.

I dislike to call attention to this matter, but being connected with no college, I feel that I can do so without being charged with selfish motives. The Southern Colleges had, many of them, sent out their catalogues setting forth a three years' course of study, and now for the Association to say to them that "neither you nor any of your graduates for 1899 can be received as members of the Association," is unjust. Some of these professors are live, active members of our AssociaTION. As already stated, this action of the Association can not bind any one, having been illegally taken; hence, the Registration Committee should be notified to proceed at. Columbus under the old law.

Yours truly, T. J. HAPPEL, Ex-Vice-President.

\section{A Handy Way to Clean Tubes.}

Elgin, Ill., Aug. 23, 1898.

To the Editor:-Being interested in the use of the hematocrit and the hematocy tometer, I wish to mention a few matters of technique which I have followed that have facilitated the the use of these instruments.

The hematocrit percentage tubes are usually accompanied with a dropper and rubber tube connection, presumably to be used for filling and cleaning them. It will be found difficult to fill a percentage tube by the use of the dropper from one drop of blood without admitting air at the same time. If the tube is perfectly clean it can be much more easily filled by placing its point in the drop of blood and allowing it to fill by capillary attraction, but the success of the procedure depends on the cleanliness of the tube. The slightest coating of fibrin in the tube prevents it from filling, but if absolute cleanliness is observed, one will experience no difficulty.

To clean the tube perfectly has been a problem which demands attention. After using a tube there will be found a deposit of flbrin which can scarcely be removed by simple washing in water, alcohol and ether. A fine cambric needle armed with a strand of mending cotton can be used to wipe the inner surface of the tube, preferably after the tube has. been thoroughly dried.

To dry the percentage tubes of the hematocrit and the measuring tube of the hematocy tometer, the use of an ordinary bicycle.pump will be found very satisfactory.

Possibly these simple procedures may have been adopted by others, but if mentioned in any of the current literature such mention has escaped my notice. Very respectfully, F. H. Jenks, M.D. 